\title{
Collecting case studies / exemplars of good practice to enrich The National Information Literacy Framework (Scotland)
}

\author{
Christine Irving
}

\begin{abstract}
This paper discusses the challenges, process and reasons for collecting case studies / exemplars of good practice from practitioners to enrich The National Information Literacy Framework (Scotland). The lessons learned show that there is a tendency for people to think they are not doing anything special and therefore do not respond to emails for exemplars of good practice. They are however once contacted happy to share their practice. It is therefore essential to use networks of contacts, leave plenty of time to talk, visit and work with people on submitting their work as a case study / exemplar. Sharing practice also contributes to professional development both for the individual and their community and to the field of research.

Background information is provided on the national framework, the project funding, the project partners and the range of examples collected for different sectors. Plus use of templates and Web 2 tools.
\end{abstract}

\section{Introduction}

\subsection{A national overarching framework}

One of the key aims of The Scottish Information Literacy Project has been the development of a national overarching framework of information literacy skills and competencies which all sectors of education can recognize and develop or which can be applied to the world of work. Equipping learners with skills needed

\section{Christine Irving}

Christine Irving is the Researcher / Project Officer of the Scottish Information Literacy Project where she developed the National Information Literacy Framework (Scotland) with cross sector partners. Previous projects she has been involved in include online interactive material for lifelong learners / post 16 year olds plus co-authoring an Information Handling Skills national qualification at Intermediate 2 for SQA (Scottish Qualifications Authority) and the accompanying assessment (NAB).

Email: christine.irving@gcal.ac.uk 
for the 21 st century is seen as a key tool for the embedding of information literacy in schools, FE, HE, and lifelong learning and for life.

With funds from Eduserv a draft framework was developed and piloted in conjunction with cross sector partners with the aim of:

- defining information literacy learning in terms of statements of skills, knowledge and understanding;

- enabling the notional levelling process and outcomes to become transparent and clearly understood by other learning providers, receiving organisations and or employers to meet the needs of the lifelong learner more effectively;

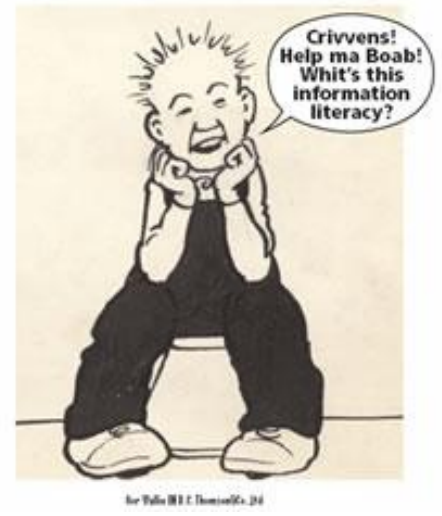

Image used with permission: DC Thomson

- supporting a continuing learning process through identifying a learning pathway within the context of SCQF (Scottish Credit Qualification Framework) (SCQF, 2005) as part of an educational guidance or personal development planning process;

- mapping the existing learning that is taking place allocating a notional level to learning outcomes utilising relevant reference points such as the SCQF generic level descriptors with the intention of providing a general shared understanding of each level which can then be linked to academic, vocational or professional practice;

- incorporating and highlight CILIP's information literacy skills and competences definition (CILIP, 2004) and SQA's Information Handling Skills Intermediate 2 qualification.

The target audience for the framework is:

- library and information professionals working in learning and teaching environments / organisations;

- learning and teaching organisations e.g. Learning and Teaching Scotland, Skills Development Scotland;

- organisations involved in qualifications and accreditation e.g. CILIP, SQA.

The draft framework levels cover:

- Schools

- Secondary Schools / Further Education Colleges

- Further / Higher Education

- Higher Education

- Lifelong learning including all information-using communities e.g. workplaces, adult literacies, community learning, public libraries

and have common skills running through them. Although there are differences in the grouping and wording of these skills, the commonality enables these skills to be learnt / developed at different levels within different sectors for information 
tasks appropriate for that level then further developed to the level other sectors require, thus creating a learning pathway for education or personal development planning process.

\section{$1.2 \quad$ Project Partners}

The development of the draft framework has been possible due to collaboration and the general aims of the project which is to:

- attract and work with partners in secondary and tertiary education, the world of work and the wider community;

- work primarily within the Scottish educational system but also to work with interested parties UK wide and abroad;

- work with relevant non governmental agencies such as Learning and Teaching Scotland, the Scottish Credit and Qualifications Framework, Scottish Qualifications Authority, Skills Development Scotland, and professional bodies such as CILIP, SCURL, SCONUL;

- research the role and importance of information literacy in the workplace both in the public and corporate sectors and work with partners in these areas;

- research the role and importance of information literacy in continuing professional development (CPD);

- engage in information literacy advocacy through all available channels and opportunities such as the Scottish Parliament and Executive, relevant NGO's and the educational and information media;

- develop links with agencies in other countries undertaking information literacy advocacy.

'Working with partners to create an information literate Scotland' has enabled the framework to develop from an initial idea discussed with a member of the advisory group to the revised online interactive framework it is today with case studies and exemplars of good practice plus news of information literacy activities, developments and strategies.

\section{Methodology}

In 2007-8 the draft framework underwent a piloting exercise with the project's advisory group, project partners from schools, further education colleges, universities and different workplaces plus adult literacy initiatives.

The project's advisory group and partners identified that the framework needed to be enriched with exemplars of good practice which would demonstrate how specific competencies can:

- be applied in practice for different subjects, levels of pupils / students and how this could be linked to the framework, the steps involved and showing the connection;

- demonstrate links to higher level complex thinking skills and innovation. 
The above would see a departure from other national frameworks in Australia, New Zealand and America that just have the skills levels. It would aim to show through the exemplars how the skills had been mapped into course design, recognising different modes of teaching and learning. For example evidence based, problem based plus target disciplines that value information and feed forward / link with further developments including educational development strategies such as:

- the Curriculum for Excellence within schools and FE sector specifically the Literacy Across Learning Outcomes and Experiences (Learning and Teaching Scotland, 2009) which illustrates the progressional nature of literacy skills (including what they refer to as information / critical literacy) and how these play an important role in all learning

- initiatives within further and higher education.

Discussions were also held with senior personnel at LTS (Learning and Teaching Scotland). All emphasised the importance of including exemplars of good practice drawn from real life experience.

Some exemplars had been identified through the draft framework piloting exercise but more were needed and an initial approach of asking for exemplars of good practice was met by silence. A new more proactive strategy had to be adopted as it seemed that people did not see their activities as 'exemplars of good practice' so there was a need to explore, identify, discuss, visit and see information literacy activities being carried out by project partners and interested parties and then ask if the activity could be used as an exemplar / case study.

On the lifelong learning side CILIP's Information Literacy definition has no levels or depths of skills required attached to it; however research carried out by the project into 'The role of information literacy in the workplace: an exploratory qualitative study' (Crawford and Irving, 2009) funded by The British Academy determined that:

- those in the workplace would need to look at how individuals define information literacy in terms of their own qualifications, training and work experience. For example Lloyd and Somerville's (2006) work with firefighters highlights smell and touch as information sources;

- those involved in adult or community learning may wish to use levels within the other sectors that they feel are appropriate.

This study helped us to increase the number of workplace partners and introduced us to Adult Literacy networks and encouraged us to look at the role of public libraries in developing information literacy training programmes.

On a government level The Scottish Government (2007) published Skills for Scotland: A Lifelong Skills Strategy. This set out their ambitions for skills, in a lifelong learning context, from cradle to grave. The Strategy set out three major areas in which change was required: a focus on individual development, a response to the needs of the economy and the demand of employers and the creation of cohesive structures. The key civil servant responsible for this strategy was identified for us by one of our workplace partners (The Scottish Government 
Information Services) and following a lengthy protracted period fruitful discussions were held resulting in an agreement that the project would submit a number of information literacy case studies from different sectors.

In addition the discussions with LTS also led to work funded by them to identify exemplars of good practice within the cross curricular area of information literacy for dissemination through their Online Service Curriculum for Excellence Sharing Practice (Learning and Teaching Scotland, 2009a) which offers an important mechanism to keep education authority and school staff informed and supported.

The addition of these exemplars to add value to the LTS Online Service by:

- facilitating access to practitioners' good practices and classroom resources within this important cross curricular area;

- demonstrating how specific information literacy competencies can be applied in practice;

- identifying exemplars linked to different levels within the curriculum, subjects and resources;

○ the exemplars matched against the National Information Literacy Framework (Scotland) standards / levels;

- the exemplars and the framework will provide school teachers with an identified standard of information literacy skills at the identified levels and contribute to the development of information literacy and media literacy skills among school pupils;

○ it should help to alleviate the concerns of teachers about their capacity to take on this work identified by Professor Dorothy Williams of Robert Gordon University (Williams and Wavell, 2006);

- providing resources that will contribute to the development of Glow which is the "world's first national intranet for education" within schools (Learning and Teaching Scotland, 2009b);

- providing information for education managers within this important cross curricular area;

- sharing expertise from library and information science research to education in a key area for the 21 st Century.

The work to be informed by, advised and supported by Project partners:

- North Lanarkshire Council, Education Resource Service;

- Information and Learning Resources, City of Edinburgh Council, Children and Families Department;

- North Ayrshire Education Resources Service. 
The above support made a big difference and thirteen case studies were identified. However the process was a much longer one than anticipated, over running the original project timescale of February 2008 - December 2008.

\section{Exemplars / case studies}

Although the exemplars / case studies were slow to come / identify we have managed to collect a range of examples for each section which are now listed within the restructured framework which is a weblog (National Information Literacy Framework Scotland, 2009).

\subsection{School case studies / exemplars of good practice}

- Information Literacy Model - ExPLORE (City of Edinburgh)

- North Ayrshire Information Literacy Toolkit - Primary Schools

- Schools toolkit for Information Literacy - Nursery - primary 7 (12 year olds) (Aberdeenshire)

- Transition from primary to secondary school (Craigholme School, Glasgow)

- Sharing practice - IL case studies (Curriculum for Excellence)

- School Information Literacy Policy (Benton Park High School, Leeds)

- Real and Relevant - Information Literacy Skills for the $21^{\text {st }}$ Century Learner (Literacy Development Officer, Curriculum for Excellence)

\subsection{Secondary school case studies / exemplars of good practice}

- Govan High staff induction programme that challenges ICT assumptions

- 1st Year English Library Research project Biography (Ardrossan Academy)

- Supporting pupils in developing their information skills in an academic context (Caldervale High School, Airdrie)

- Helping senior pupils with research for Higher History extended essays (Dunbar Grammar School)

- East Lothian School Librarians IL activities

- Largs Academy - information literacy activities

- James Gillespie High School - developing S1 information literacy

- Information literacy using the ExPLORE model (Gracemount High School, Edinburgh)

- Information literacy and the draft CfE Science Outcomes (Holy Rood High School)

- Information Literacy Audit \& School Information Literacy working group (Oban High School) 


\subsection{FE college case studies / exemplars of good practice}

- IL diagnostic assessment @ Carnegie College

\subsection{HE college case studies / exemplars of good practice}

- University of Abertay - Appendix D

- Loughborough University - Appendix E

Although the Loughborough example is not a Scottish example it does demonstrate how two different universities have used the same set of skills - the SCONUL 7 Pillars Model as their starting point but have embedded / introduced them differently.

Other HE /university case studies / exemplars of good practice added include:

- Dundee University and three Dundee High Schools

- Glasgow Caledonian University - iLearn Framework

\subsection{Workplace case studies / exemplars of good practice}

- NHS Scotland information literacy competency framework

- Skills for Scotland: A Lifelong Skills Strategy

- Scottish Government Information Services IL activities

\subsection{Public library case studies / exemplars of good practice}

- Inverclyde Libraries - Greenock; Dumfries and Galloway Libraries Ewart Library; Glasgow Libraries - Mitchell Library and Glasgow REAL Learning Centres

The idea of using a weblog to facilitate the transformation of the 68 page pdf draft information literacy framework into a more flexible tool that enabled case studies / exemplars of good practice to be added emerged as experience with the project blog grew and the potential of what could be done with blogs apart from blogging. The static pages would contain the framework details whilst the blog postings would facilitate the communication of any news, activities and developments and enable interested parties to comment on any of the postings or on the framework pages.

It is early days yet but the idea seemed to be well received by the project advisory group then by the project's open meeting in September 2009.

\section{Lessons learned}

Calls for exemplars of good practice or best practice do not work on their own. Whether it is the actual term or words used people are reluctant to step forward for whatever reasons. Another study Learning Literacies for a Digital Age (LLiDA) 
project (2009) confirmed similar difficulties. Whether this is a nationality or professional trait or a combination of both it leaves the collector with the task of seeking out activities, investigating them and then making a decision on whether it fits the qualities they think makes a good exemplar of good / best practice or case study. It is necessary to use a variety of means but using networks of contacts, getting out and about talking to and seeing first hand what people are doing is an amazing experience which despite being time consuming is definitely worthwhile and has proved successful.

Whilst the LTS (2009) sharing practice funded case studies used a template (Figure 1) which resulted in a professional looking tabbed mini website providing some consistency to layout and preventing scrolling as the text is broken up, it did take some effort to convince those providing the case studies that the template was there to help them not make more work for them.

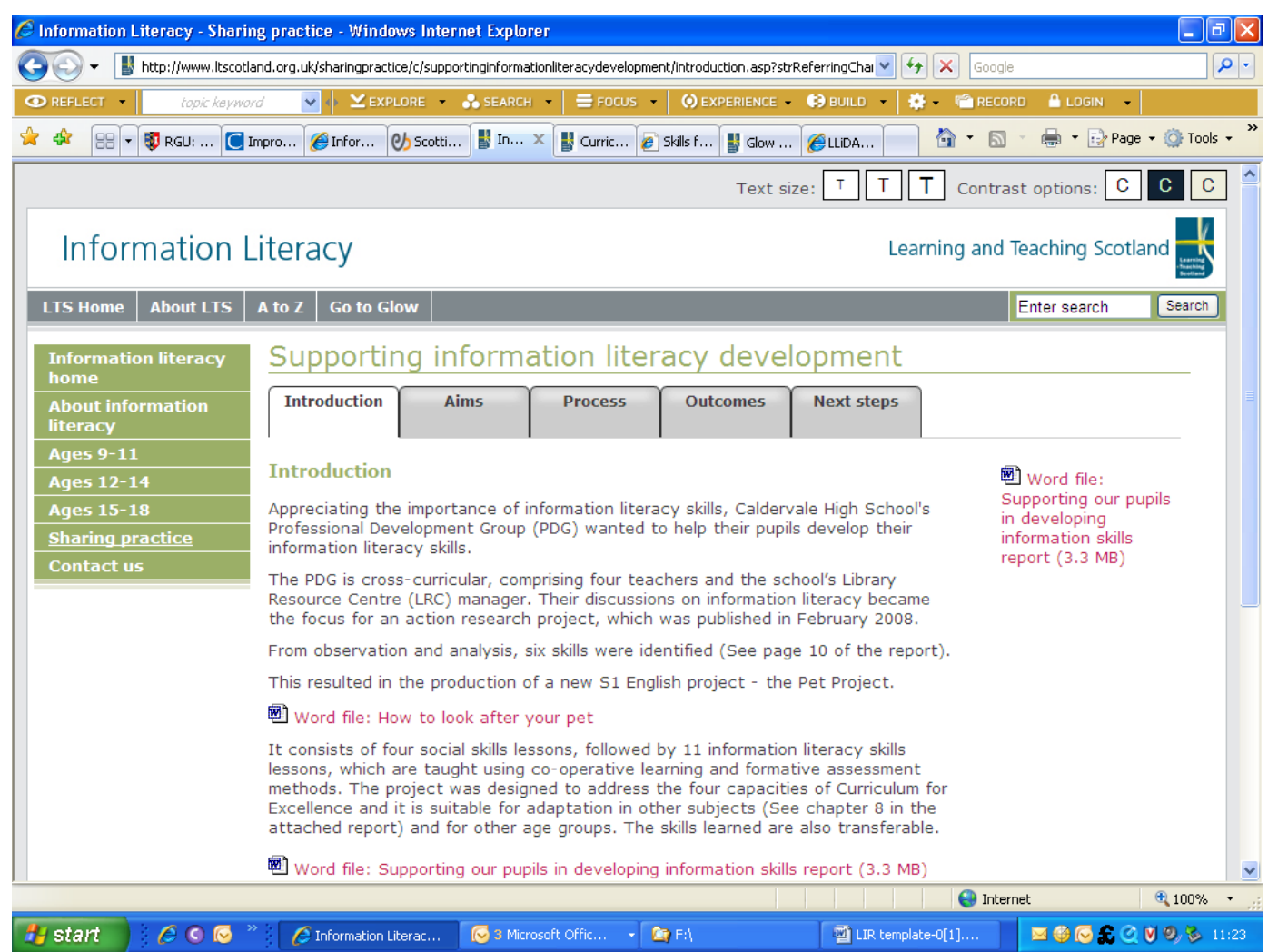

\section{Figure 1: Screenshot of online LTS case study}

However the project did not have the IT resources that LTS have so the decision was taken to summarise the activity with contact details listed for anyone who wanted more information given. Hopefully the facility of being able to comment on the exemplar or the individual whose exemplar it is being able to provide an update for all to see may prove more useful.

Interestingly the LLiDA project mentioned above have used a Wiki, another Web 2.0 tool, to display their snapshots / exemplars. 


\section{Conclusion}

So was it worth all the effort of collecting case studies / exemplars? Definitely, as it provides ideas and benchmarking possibilities not only for those new to the profession or sector but to the existing LIS practitioner and hopefully will encourage sharing practice and collaborative working. It also gives the research community insights into what information literacy activities LIS practitioner are involved in.

Whilst the information literacy activities need to be reviewed and updated to incorporate new resources, tools, technology it does provide a useful snapshot of what is happening in Scotland at the moment and possible areas for research and development.

In addition "Sharing good practice within and beyond their own establishments and cluster" along with "personal reading and research, including engaging with online resources and discussing and sharing good practice through these resources" are recognised as part of best professional development (The Scottish Government, 2009, 4-5). Not just for the individual concerned but also their community and interested parties and contributes to the field of research.

\section{References}

CILIP (2004) CILIP information literacy definition. URL:

http://www.cilip.org.uk/get-involved/advocacy/learning/informationliteracy/pages/definition.aspx

[accessed 25.01.2010].

Learning and Teaching Scotland (2009) Curriculum for Excellence - Sharing

Practice. URL:

http://www.ltscotland.org.uk/curriculumforexcellence/sharingpractice/index.asp [accessed 07.10.09].

Learning and Teaching Scotland (2009a) Glow Scotland. URL:

http://www.ltscotland.org.uk/glowscotland/about/index.asp [accessed 07.10.09].

Learning and Teaching Scotland (2009b) Information literacy: Sharing practice. URL: http://www.ltscotland.org.uk/informationliteracy/sharingpractice/index.asp [accessed 07.10.09].

Learning Literacies for a Digital Age (LLiDA) (2009) URL: http://www.academy.gcal.ac.uk/llida/ [accessed 07.10.09].

Lloyd, A. and Somerville, M. (2006) Working information, Journal of Workplace Learning [online], 18 (3), 186-198. URL:

http://www.emeraldinsight.com/Insight/viewContentItem.do;jsessionid=82CC989 E3E974CE452002C759CF9AB65? content Type=Article\&contentId=1546157 [accessed 07.10.09].

National Information Literacy Framework Scotland (2009) URL: http://caledonianblogs.net/nilfs/\# [accessed 07.10.09]. 
The Scottish Government (2007) Skills for Scotland: A Lifelong Skills Strategy URL: http://www.scotland.gov.uk/Topics/Education/skills-strategy [accessed 07.10.09].

The Scottish Government (2009) towards a professional development strategy for curriculum for excellence: management board discussion paper. URL:

http://www.ltscotland.org.uk/publications/t/publication tcm4565600.asp?strRefer ringChannel=curriculumforexcellence [accessed 07.10.09].

SCQF (2005) Scottish Credit Qualification Framework. URL: http://www.scqf.org.uk/ [accessed 25.01.2010].

Williams, D.A. and Wavell, C. (2006) Teachers' Conceptions of Information Literacy in Relation to their Classroom Practice. URL:

http://www.rgu.ac.uk/abs/research/page.cfm?pge=13088\# [accessed 07.10.09].

\section{Acknowledgement}

The project would like to acknowledge the following funding bodies: Esmee Fairbairn Foundation; Eduserv; Learning and Teaching Scotland (LTS) for their belief in the project and the project team.

Thanks go to the Project Advisory Group, Project Partners and all case study participants whose contributions are gratefully appreciated. Thanks also go to the Project Director John Crawford whose support and belief in me contributes to my professional development. 